\title{
Patients' Assessments of Tooth Sensitivity Increase One Day Following Different Whitening Treatments
}

\section{Procjena pacijenata o preosjetljivosti zuba dan nakon različitih postupaka izbjeljivanja}

\author{
${ }^{1}$ Private dental office Floss Gloss, Sarajevo, Bosnia and Herzegovina \\ Privatna stomatološka ordinacija Floss i Gloss, Maršala Tita 5, Sarajevo, Bosna i Hercegovina \\ 2 Dental practice, Community Health Center Osječko-baranjska County, Osijek, Croatia \\ Stomatološka ordinacija Doma zdravlja Osječko-baranjske županije, Petra Krešimira IV. 6, Osijek, Hrvatska \\ 3 Department of Removable Prosthodontics, School of Dental Medicine, University of Zagreb, Zagreb, Croatia \\ Zavod za mobilnu protetiku Stomatološkog fakulteta Sveučilišta u Zagrebu, Hrvatska
}

Received: February 14, 2021

Accepted: August 25, 2021

Address for correspondence Amar Piknjač Private dental office Floss\&Gloss, Maršala Tita 5, 71000 Sarajevo Bosnia and Herzegovina

E-mail: amar.piknjac@gmail.com

MeSH terms: Tooth Bleaching; Dentin Sensitivity; Tooth Bleaching Agents Author keywords: Tooth Sensitivity; In-office Whitening; At-home Whitening

\section{Introduction}

Tooth color is one of the most important esthetic visual parameters in dental medicine (1). Patients' demands for esthetic appearance have increased over the past decade, including correction of their tooth color $(2,3)$. Therefore, tooth whitening becomes an increasingly requested dental technique considered more conservative for improving tooth color, thus avoiding more no invasive procedures such as for crowns or veneers (4).

Today there are two types of dentist-supervised whitening techniques for vital teeth: at-home whitening and in-office whitening (5). Both procedures provide whitening agents containing hydrogen peroxide (HP) or carbamide peroxide (CP) over the vestibular tooth surface $(6,7)$. CP is a well-accepted agent for home whitening procedure where the patients apply the gel on the tooth surface using a customized tray. A 10\% CP was considered as a golden standard material for home whitening but to increase the efficacy of the material, higher concentrations of CP are being used $(8,9)$. The main advan-

\section{Uvod}

Boja zuba jedan je od najvažnijih estetskih vizualnih parametara u dentalnoj medicini (1). Zahtjevi pacijenata za ljepšim izgledom u posljednjem su se desetljeću povećali, uključujući i korekciju boje zuba $(2,3)$. Zato je izbjeljivanje postalo čest stomatološki postupak koji se smatra minimalno invazivnim te se taj način izbjegavaju invazivniji zahvati poput izrade krunica ili ljuskica za korekciju boje zuba (4).

Danas se primjenjuju dvije metode za izbjeljivanje vitalnih zuba - izbjeljivanje kod kuće i izbjeljivanje u ordinaciji (5). Oba postupka zahtijevaju sredstva za izbjeljivanje koja sadržavaju vodikov peroksid (HP) ili karbamidni peroksid (CP) i oba se apliciraju na vestibularnu površinu zuba $(6,7)$ CP je dobro prihvaćeno sredstvo za postupke izbjeljivanja kod kuće gdje pacijenti prilagođenom individualnom udlagom nanose gel na površinu zuba. 10-postotni CP smatra se zlatnim standardom kao materijal izbora za kućno izbjeljivanje, ali za povećanje njegove učinkovitosti mora se odabrati veća koncentracija $(8,9)$. Glavne prednosti tehnike izbjelji- 
tages of home whitening technique are reduced chair time, ease to use, less gingival irritation and lower tooth sensitivity (10). Manufacturers usually incorporate fluoride and desensitizing products in at-home whitening agents, such as potassium nitrate, that reduce tooth sensitivity TS (11). On the other hand, in-office tooth whitening technique uses much higher concentration of HP (15-40\%), which produces faster tooth whitening results visible after only one visit (12). Despite the advantage of achieving faster results, the main disadvantages of this method are longer chair time, gingival irritation and higher risk of TS (13). A higher concentration of HP increases the activation of inflammatory receptors in the pulp chamber and causes tooth sensitivity (14). Some manufacturers have also incorporated fluoride or desensitizing products into the inoffice gel formula to decrease sensitivity (4).

Many studies have already reported a certain degree of TS following different whitening procedures using various products containing different concentrations of HP or CP (1520).

The aim of this randomized clinical study was to compare tooth sensitivity before and 1 day following in-office and athome whitening treatments using different concentrations of $\mathrm{HP}$ and CPs in patients self-reporting mild sensitivity prior to the treatment. The null hypothesis tested was that the application of different concentrations of HP and CPs had no effect on both tooth sensitivity increase and whitening results.

\section{Materials and methods}

\section{Sample}

The study was performed upon the approval from the Ethics Committee of the School of Dental Medicine University of Zagreb. All participants were provided with a patient information sheet and were required to sign informed consent forms.

In order to determine the sample size, the Univariate Analysis of Variance was performed as a pilot on 10 subjects who had undergone whitening procedures using $40 \% \mathrm{HP}$, $16 \% \mathrm{CP}$ and $10 \% \mathrm{CP}$, respectively. Color differences $(\Delta \mathrm{E})$ were calculated with $\mathrm{p}$ value set to $<=01$. With the effect size produced of 0.55 in this sample size, there was $99 \%$ chance to detect the difference in $\mathrm{dE}$ values (between different concentrations of whitening agents). Upon these results, we have decided to double the sample size aiming to achieve a total of 60 participants in the study. Participants were recruited from the group of postgraduate students of School of Dental Medicine. After pre investigation and post investigation, the exclusion criteria were determined and the final number of participants was set of on 60 , and it was partially randomized in the group which reported higher pain threshold. Finally, 41 women and 19 men (mean 27.5 and 34.5 years; respectively), using the inclusion and exclusion criteria and tooth sensitivity self-assessment as described in Table 1 and Figure 1 (5 excluded upon the criteria and 2 upon tooth sensitivity selfassessment) were selected.

Dropouts (2 participants were excluded due to the failures during the at-home whitening procedure) were replaced with new participants to achieve desired power of the statis- vanja kod kuće su kraće vrijeme provedeno u stomatološkoj ordinaciji, jednostavnost korištenja, slabija iritacija gingive i manja osjetljivost zuba (10). Proizvođači obično u sredstva za izbjeljivanje kod kuće ugrađuju fluoride i desenzibilizirajuće proizvode, poput kalijeva nitrata, koji smanjuju osjetljivost zuba OZ (11). S druge strane, tehnika izbjeljivanja zuba u ordinaciji zahtijeva mnogo veću koncentraciju HP-a $(15-40$ $\%)$, no rezultati se brže postižu i vidljivi su već nakon jednog posjeta (12). Unatoč prednosti kao što je postizanje bržih rezultata, glavni nedostatci te metode su više vremena provedenog u stomatološkoj ordinaciji, iritacija gingive i veći rizik od preosjetljivosti zuba (13). Veća koncentracija HP-a povećava aktivaciju upalnih receptora u pulpnoj komori i izaziva osjetljivost zuba (14). Neki su proizvođači uključili i fluoridne ili desenzibilizirajuće proizvode $\mathrm{u}$ formulu gela za izbjeljivanje u ordinaciji kako bi smanjili osjetljivost (4).

U mnogim istraživanjima već je dokazan određeni stupanj OZ-a poslije različitih postupaka izbjeljivanja proizvodima koji sadržavaju različite koncentracije HP-a ili CP-a (15 -20 ).

Cilj ove randomizirane kliničke studije bio je usporediti osjetljivost zuba prije postupka izbjeljivanja u ordinaciji ili kod kuće te dan poslije korištenja različitih koncentracija HP-a i CP-a kod pacijenata koji su sami prijavili blagu osjetljivost prije liječenja. Testirana nulta hipoteza glasila je da primjena različitih koncentracija HP-a i CP-a ne utječe na povećanu osjetljivost zuba i rezultate izbjeljivanja.

\section{Materijal i metode}

Uzorak

Istraživanje je odobrilo Etičko povjerenstvo Stomatološkog fakulteta Sveučilišta u Zagrebu. Svi sudionici potpisali su informirani pristanak.

Da bi se odredila veličina uzorka, provedeno je pilot-istraživanje na 10 ispitanika kojima je obavljen postupak izbjeljivanja 40-postotnim HP-om te 16-postotnim i 10-postotnim $\mathrm{CP}$-om univarijantnom analizom varijance. Izračunate su razlike u boji $(\Delta \mathrm{E}) \mathrm{s} \mathrm{p}$ vrijednošću postavljenom na $<=01$. i veličinom učinka od 0,55 te je u tom uzorku postojala 99-postotna mogućnost za otkrivanje razlike u vrijednostima $\Delta \mathrm{E}$ (između različitih koncentracija sredstava za izbjeljivanje). Nakon tih rezultata odlučeno je za potrebe istraživanja udvostručiti veličinu uzorka na ukupno 60 sudionika. Svi su bili odabrani među poslijediplomskim studentima Stomatološkog fakulteta, a na osnovi kriterija za isključenje konačan broj sudionika bio je 60 , te je djelomično randomiziran u skupini koja je prijavila viši prag boli. Na kraju je u ispitivanju sudjelovalo 19 muškaraca i 41 žena (prosječno 27,5 i 34,5 godina), a odabrani su na temelju kriterija za uključivanje i isključivanje te samoprocjene osjetljivosti zuba opisane u tablici. 1. i slici 1. (5 ispitanika isključeno je prema kriterijima, a 2 prema samoosjetljivosti zuba).

Ispitanici koji su isključeni iz studije (2 sudionika zbog pogrešaka tijekom postupka izbjeljivanja kod kuće) zamijenjeni su novima zbog statističke analize. Svi su željeli promijeniti boju zuba iz kozmetičkih razloga. Kod $50 \%$ sudionika početna boja bila je $\mathrm{A} 1$, a kod drugih $50 \%$ A2 ili tamnija. 
tical analysis. All the participants wanted to change the color of their teeth for cosmetic reasons. In $50 \%$ of the participants the initial color was A1, and in 50\% A2 or even darker.

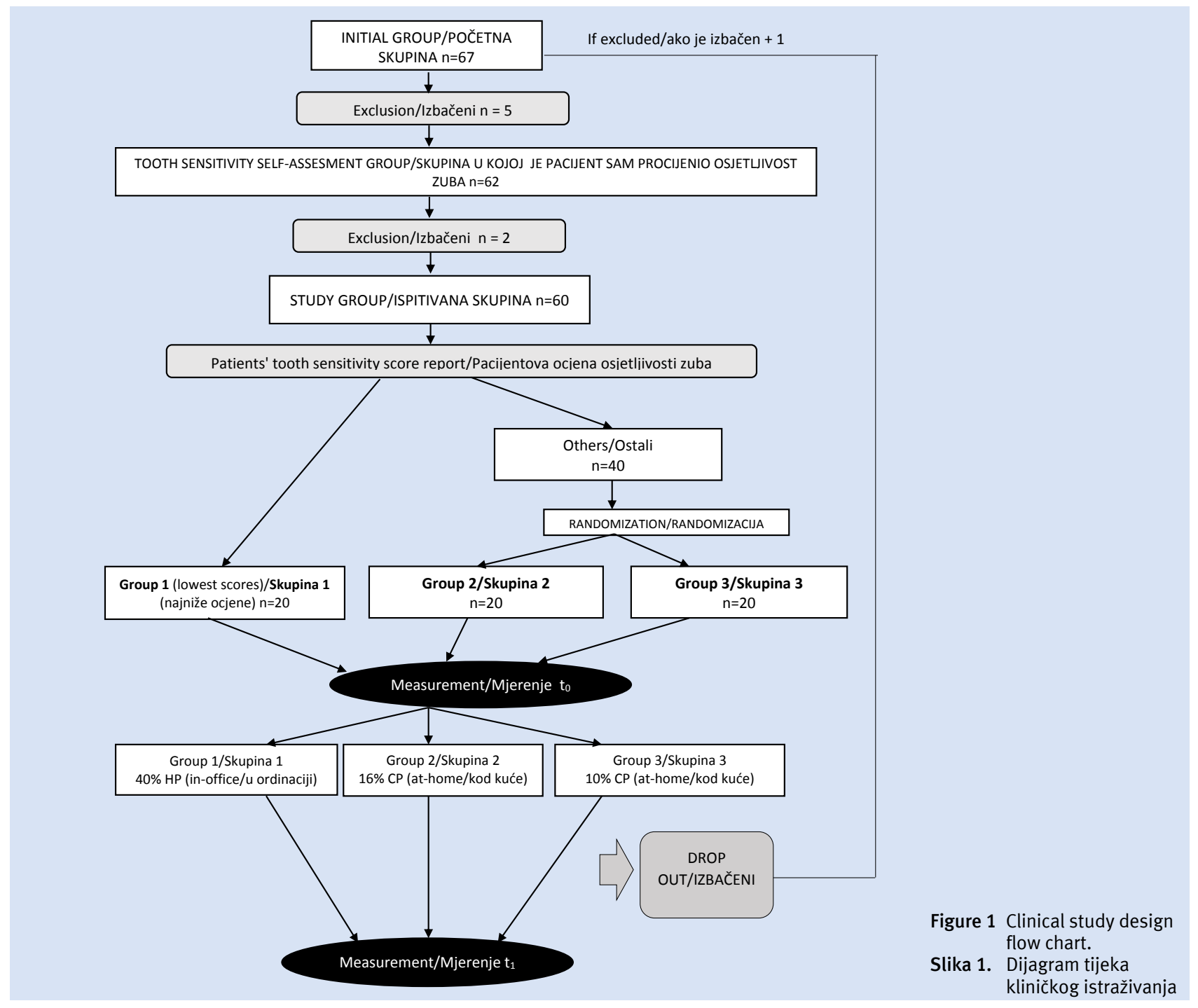

Table 1 Criteria used in this study.

Tablica 1. Kriteriji korišteni u ovom istraživanju

\section{Inclusion criteria $\bullet$ Kriteriji uključivanja}

adult (18-70 years) $\bullet$ odrasla osoba $(18-70$ godina $)$

minimum of 20 natural teeth, including incisors and canines in both arches • minimalno 20 prirodnih zuba, uključujući sjekutiće i očnjake u oba luka

willing to sign consent form $\bullet$ spremni potpisati informativni pristanak

willing to change the color of their teeth for cosmetic reasons - spremni promijeniti boju zuba iz kozmetičkih razloga willing to return for post whitening evaluation $\bullet$ spremni vratiti se na procjenu izbjeljivanja nakon toga postupka good oral hygiene $\bullet$ dobra oralna higijena

no caries on teeth to be whitened $\bullet$ nema karijesa na zubima za izbjeljivanje

\section{Exclusion criteria $\bullet$ Kriteriji isključenja}

currently undergoing treatment for caries, gingivitis, or periodontitis, or having undergone or currently undergoing orthodontic treatment $\bullet$ trenutačno se obavljaju restaurativni, endodonstki, parodontni ili ortodontski postupci

structural alteration of tooth structure, or alternation of oral mucosa $\bullet$ promjene $\mathrm{u}$ strukturi zuba ili na oralnoj sluznici

medical condition that the investigator believed might compromise the study or the individual's safety • zdravstveno stanje za koje se pretpostavlja da bi moglo ugroziti studiju ili sigurnost pojedinca

existing dental restorations in teeth to be whitened $\bullet$ postojeće zubne nadoknade na zubima koje treba izbijeliti

use of tobacco products during previous 30 days $\bullet$ korištenje duhanskih proizvoda posljednjih 30 dana

pregnant or breast-feeding women $\bullet$ trudnice ili dojilje

tetracycline-stained teeth or fluorosis $\bullet$ tetraciklinska obojenja ili fluoroze 


\section{Participants' randomization upon tooth sensitivity} assessment

After the exclusion of additional 5 participants from the initial group who did not meet the inclusion criteria, the participants were asked to self-assess any noticeable, short-term, transient and sporadic tooth sensitivity experienced in the past year on a Numerical Rating Scale (NRC) circling the number between 0 and 10 , wherein 0 represented no pain and 10 represented the worst pain ever possible (21). Further two participants did not report any pain, and were therefore excluded from the further studies (Figure 1).

Based on the obtained results, 20 patients with the lowest scores were included in 40\% HP in-office whitening treatment group. The rest of them were randomly distributed to one of two at-home whitening treatment groups (16\% and $10 \% \mathrm{CP}$ )(Figure 1).

One day following whitening treatment, the participants were asked to score possible occurrence of the previously described pain using the same NRC scale.

\section{Positioning jig}

The teeth of the participants were professionally cleaned (Proxyt RDA 36; Ivoclar Vivadent, Schaan, Liechtenstein). One alginate (Hydrogum 5, Zhermack, Badia Polesine (RO), Italy) impression of the maxillary arch was made, and a stone model (Fuji rock EP Classic line; GC, Tokyo, Japan) was produced to fabricate a modified form of whitening tray, 1-mm-thick thermoplastic tray material and thermoforming unit (Erkodent, Pfalzgrafenweiler, Germany), to make a positioning jig to ensure the placement of the tip of the spectrophotometer in the same position at every color measurement (at baseline, and 7 days following the treatment). An impression of the tip of the probe of the device was made and a cast was fabricated. The spectrophotometer probe cast was used as a stamp guide to mark the whitening tray. The facial middle-third of the maxillary teeth was marked with the spectrophotometer tip cast. The facial marks were cut, leaving an opening for the placement of the s probe. Prior to color measurement, the custom jig was positioned in the patient's mouth, and the probe was positioned into the jig opening. The subjects were asked to brush their teeth at least twice a day in order to maintain high level of oral hygiene.

\section{In-office whitening treatment}

Twenty participants chosen for in-office whitening treatment in this study were chairside treated with $40 \% \mathrm{HP}$ (Opalescence Boost: PF 40, Ultradent, USA). Prior to treatment, protective lip cream, and a light-cured resin barrier Opal Dam (Ultradent, South Jordan, UT, USA) for gingival protection were applied (included in the kit). To prevent saliva from flowing through embrasures of anterior teeth, a saliva ejector and cotton rolls were used in the sublingual region. An expanded lip retractor was used to protect the lips. An Ultradent IsoBlock (Ultradent, South Jordan, UT, USA) was used to keep the tongue in a safe position. For Opalescence Boost PF, the activator was mixed into the whitening agent using an adequate syringe. The mixture was then applied, 1-2 mm thick, to buccal surfaces of the teeth (canine to canine) of the maxillary arch. It remained there for

\section{Randomizacija sudionika nakon procjene osjetljivosti} zuba

Nakon isključenja pet sudionika iz početne skupine koji nisu zadovoljili kriterije, ostali su zamoljeni da sami procijene sve uočljive, kratkoročne, prolazne i povremene osjetljivosti zuba unatrag godinu dana i da je označe na numeričkoj ljestvici (NRC) između 0 i 10, gdje 0 ne označuje bol, a 10 je najveća moguća bol (21). Dva sudionika nisu prijavila nikakvu bol pa su isključeni (slika 1.).

$\mathrm{Na}$ temelju dobivenih rezultata 20 pacijenata s najnižim rezultatima uključeno je u skupinu za izbjeljivanje u ordinaciji 40-postotnim HP-om. Ostali su nasumično raspoređeni u jednu od dviju skupina za postupak kod kuće (16-postotni i 10-postotni CP) (slika 1.).

Prvi dan poslije postupka izbjeljivanja sudionici su zamoljeni da ocijene moguću pojavu opisane boli s pomoću iste NRC ljestvice.

\section{Žig za pozicioniranje}

Sudionicima su zubi profesionalno očišćeni (Proxyt RDA 36; Ivoclar Vivadent, Schaan, Liechtenstein). Uzet je jedan alginatni (Hydrogum ${ }^{\oplus}$, Zhermack, Badia Polesine (RO), Italija) otisak maksilarnoga luka te je izliven sadreni model (Fuji rock EP Classic linija; GC, Tokio, Japan) za izradu modificirane udlage za izbjeljivanje zuba od termoplastičnoga materijala debljine $1 \mathrm{~mm}$ i uređajem (Erkodent, Pfalzgrafenweiler, Njemačka) da bi se napravila šablona za pozicioniranje, tj. da bi se osiguralo postavljanje vrha spektrofotometra u jednaki položaj pri svakom mjerenju boje (na početku i 7 dana nakon tretmana). Uzet je otisak vrha sonde spektrofotometra i on je izliven. Taj vršak korišsten je kao vodič za žigove za označivanje udlage za izbjeljivanje. Srednja trećina vestibularane površine zuba označena je tim vrškom. Oznake su izrezane i ostavljen je samo otvor za postavljanje spektrofotometra. Prije mjerenja boje prilagođena termoplastična udlaga stavljena je u usta pacijenta, a spektrofotometar je postavljen u otvore. Ispitanici su zamoljeni da peru zube najmanje dva puta na dan kako bi održali visoku razinu oralne higijene.

\section{Tretman izbjeljivanja u ordinaciji}

Dvadeset sudionika odabranih za izbjeljivanje u ordinaciji bili su tretirani 40-postotnim HP-om (Opalescence Boost: PF 40, Ultradent, SAD). Prije postupka primijenjena je zaštitna krema za usne i svjetlosnopolimerizirajuća barijera OpalDam (Ultradent, South Jordan, UT, SAD) za zaštitu gingive (uključena u komplet). Kako bi se spriječilo istjecanje sline kroz brazde prednjih zuba, u podjezičnoj regiji korišteni su sisaljka i staničevina. Usta su bila zaštićena retraktorom za usne. Da bi jezik bio u sigurnom položaju, korišten je Ultradent IsoBlock (Ultradent, South Jordan, UT, USA). $\mathrm{Za}$ Opalescence Boost PF, aktivator je odgovarajućom štrcaljkom umiješan u sredstvo za izbjeljivanje. Zatim je 1 do $2 \mathrm{~mm}$ smjese tri puta po 20 minuta naneseno na vestibularne površine zuba maksilarnoga luka (od očnjaka do očnjaka). Tijekom procesa nisu korištene svjetiljke. Sredstvo je svaki put 
twenty minutes. There were three applications. No heat or special lamps were used to complete the process. The agent was removed using suction and gauze only for a new application. After the third, last, application, the teeth were rinsed with water and the gingival isolation and lip retractor were removed. Both the participants and the dentist wore protective glasses during the treatment.

\section{At-home whitening treatment}

In participants chosen for one of two at-home whitening treatments in this study ( 40 of them) maxillary and mandibular alginate impressions were made (Aroma fine plus fast set, GC, Tokyo, Japan), and stone casts were poured (Fuji rock EP Classic line, GC, Tokyo, Japan). The custom whitening trays were then made by using a 1 -mm-thick thermoplastic tray material and thermoforming unit (Erkodent, Pfalzgrafenweiler, Germany). All excess was trimmed just short of the gingival margin. The participants were than randomly divided in two groups of 20 and each group was delivered with different concentration of CP (Opalescence PF 16\% and 10\%, Ultradent, South Jordan, UT, USA). They were instructed to use their custom trays with the whitening gel for 14 consecutive nights, for at least six hours per night.

\section{Instrumental color measurement}

Instrumental color measurement was performed on six maxillary anterior teeth before whitening (baseline- $\mathrm{t}_{0}$ ) and 1 day following whitening treatment $\left(t_{1}\right)$. The VITA Easyshade Advance 4.0 (VITA Zahnfabrik, Bad Sackingen, Germany) spectrophotometer was used and calibrated according to the manufacturer's instructions, with the operating mode set to single shade measurement. To provide accurate repositioning of the spectrophotometer probe and measurement of the middle third of the labial tooth surface over time, a custom positioning jig was made for each participant, as described in the previous chapter. The spectrophotometer measured the tooth shades based on the CIE L*a*b* color notation system. CIE $\mathrm{L}^{*} \mathrm{a}^{*} \mathrm{~b}^{*}\left(\Delta \mathrm{E}_{\mathrm{ab}}\right)$ color differences were calculated using formula:

$$
\Delta E_{a b}^{*}=\sqrt{\left(L_{2}^{*}-L_{1}^{*}\right)^{2}+\left(a_{2}^{*}-a_{1}^{*}\right)^{2}+\left(b_{2}^{*}-b_{1}^{*}\right)^{2}}
$$

Repeatability, accuracy and reliability of this device has already been tested $(23,24)$.

\section{Statistical analysis}

Data were statistically analyzed using statistical program SPSS 19.0 (SPSS, Chicago, IL, USA).

Normality of distribution was evaluated using the Saphiro-Wilk test and by inspection of data distribution graphs. Data were not normally distributed for variables about tooth sensitivity $(P<0.05)$ with the exception of the tooth sensitivity variable assessed 1 day after the whitening treatment using $40 \% \mathrm{HP}(P>0.05)$, and they were normal for color measurements $(P>0.05)$.

Marginal homogeneity was performed to test the difference between patients' assessments of tooth sensitivity within each whitening treatment before and 1 day after it. The KruskalWallis test was used to determine whether there were any differences in patients' tooth sensitivity assessments between three uklonjeno usisavanjem i gazom. Nakon treće, posljednje primjene, zubi su isprani vodom i uklonjeni su gingivna izolacija i retraktor. Ispitanici i doktor dentalne medicine imali su tijekom postupka zaštitne naočale.

\section{Tretman izbjeljivanja kod kuće}

Sudionicima odabranima za jedan od dvaju tretmana za izbjeljivanje kod kuće (njih 40) uzeti su alginatom otisci gornje i donje čeljusti (Aroma fine plus fast set, GC, Tokio, Japan) te su izliveni sadreni modeli (Fuji rock EP Klasična linija, GC, Tokio, Japan). Prilagođene udlage za izbjeljivanje izrađene su na uređaju (Erkodent, Pfalzgrafenweiler, Njemačka) od termoplastičnog materijala debljine $1 \mathrm{~mm}$. Sav višak termoplastičnog materijala iznad ruba gingive izrezan je i uklonjen. Sudionici su zatim nasumično podijeljeni u dvije skupine od po 20 i svakoj je dana drukčija koncentracija CP-a (Opalescence PF 16 \% i 10 \%, Ultradent, South Jordan, UT, SAD). Dobili su upute da svaku noć tijekom 14 noći najmanje 6 sati nose individualne udlage s gelom za izbjelivanje.

\section{Instrumentalno mjerenje boje}

Instrumentalno mjerenje boje obavljeno je na šest prednjih zuba gornje čeljusti prije izbjeljivanja (početno stanje $\mathrm{t} 0$ ) i dan poslije toga postupka (t1). Spektrofotometar VITA Easyshade Advance $4.0^{\circ}$ (VITA Zahnfabrik, Bad Sackingen, Njemačka) korišten je i kalibriran prema uputama proizvođača, a način rada postavljen je na jednokratno mjerenje boje zuba. Kako bi se omogućilo točno postavljanje spektrofotometara i mjerenje srednje trećine vestibularne površine zuba tijekom vremena, za svakog je sudionika napravljena prilagođena udlaga za pozicioniranje kako je već opisano. Spektrofotometrom je izmjerena boja zuba na temelju CIE $\mathrm{L}^{*} \mathrm{a}^{*} \mathrm{~b}^{*}$ sustava za označavanje boja. CIE L*a*b* $(\Delta \mathrm{Eab})$ razlike u boji izračunate su s pomoću formule:

$\Delta E_{a b}^{*}=\sqrt{\left(L_{2}^{*}-L_{1}^{*}\right)^{2}+\left(a_{2}^{*}-a_{1}^{*}\right)^{2}+\left(b_{2}^{*}-b_{1}^{*}\right)^{2}}(22)$.

Ponovljivost, točnost i pouzdanost toga uređaja već je ispitana i dokazana $(23,24)$.

\section{Statistička analiza}

Podatci su statistički analizirani u programu SPSS 19.0 (SPSS, Chicago, IL, SAD).

Normalnost distribucije procijenjena je Saphiro-Wilkovim testom i pregledom grafikona distribucije podataka. Kod osjetljivosti zuba sve varijable, osim one procijenjene dan poslije završenoga intenzivnog izbjeljivanja 40-postotnim HPom $(\mathrm{p}>0,05)$, nisu bile normalno distribuirane $(\mathrm{p}<0,05)$, a varijable mjerenja boje normalno su distribuirane $(\mathrm{p}>0,05)$.

Marginalna homogenost provedena je da bi se ispitala razlika između sudionikove procjene osjetljivosti zuba tijekom svakog tretmana za izbjeljivanje prije i dan poslije. KruskalWallisov test upotrijebljen je za utvrđivanje razlike u ispitanikovim procjenama osjetljivosti zuba između triju različitih postupaka izbjeljivanja prije i dan poslije, te Mann Whit- 
different whitening treatments before and 1 day after it, and the Mann Whitney tests for post hoc corrections to conduct paired comparison between these three whitening treatment groups.

One-way ANOVA was used to test the differences between three different mean $\Delta \mathrm{E}$ values and Bonferroni corrected post hoc tests (paired t tests) were used to find the differences within three different $\Delta \mathrm{E}$ values. The level of significance was set to $0.05(5 \%)$.

\section{Results}

The distribution of patients' assessment of tooth sensitivity before and 1 day following three different whitening treatment was found not to be normal in majority of the variables $(P<0.05)$ (Figure 2; Table 1). Both Skewness and Kurtosis values in patients' estimated scores indicated of a mild asymmetry from the bell curve, with a slight shift towards left (lower scores) and the lower peeks compared to normal distribution (Figure 2). The only variable with normal distribution was the patients' assessment of tooth sensitivity 1 day after the whitening treatment using $40 \% \mathrm{HP}(P>0.05)$ (Figure 2; Table 1). Therefore, non-parametric statistical tests were conducted in the further analysis.

The results of the marginal homogeneity tests revealed a statistically significant difference within scores related to sensitivity of their teeth given by patients before and 1 day following whitening treatments using $40 \% \mathrm{HP}, 16 \% \mathrm{CP}$ and $10 \% \mathrm{CP}(P=0.000,0.000$ and 0.008 , respectively)(Figure 3$)$. The patients' scores 1 day following each of the treatments were significantly higher compared to baseline scores (Figure $3)(P<0.05)$. Mean values at the baseline and 1 day after the whitening treatment using $40 \% \mathrm{HP}$ were 1.4 and 6.2 , using $16 \%$ CP 1.9 and 3.0, and after 10\% CP 1.7 and 2.2, respectively (Figure 3; Table 2) $(P<0.05)$.

At the same time, baseline scores in all three different whitening treatment groups did not differ and the KruskalWallis test revealed only small differences in mean ranks between them (Table $3 ; P>0.05$ ). On the other hand, scores assessed 1 day following treatments significantly differed, with highest mean ranks for 40\% HP in-office whitening treatment and lowest mean ranks for 10\% CP at-home whitening treatment (Table 3; $P<0.05$ ). Using the Mann-Whitney test for post hoc correction with the significance set to $P=0.016$ ( $P=0.05 / \mathrm{n}$ of groups), this difference was confirmed to be significant only between scores for $40 \% \mathrm{HP}$ and $10 \% \mathrm{CP}$ whitening treatments.

The distribution of mean $\Delta \mathrm{E}_{\mathrm{ab}}$ values in three different whitening treatment groups was normal (Table 4) $(P>0.05)$. One-way ANOVA test confirmed the presence of statistically significant differences between mean $\Delta \mathrm{E}_{\mathrm{ab}}$ values. In $40 \%$ $\mathrm{HP}$ in-office whitening treatment, the mean color change was 3.3 and in both $16 \% \mathrm{CP}$ as well as $10 \% \mathrm{CP}$ at-home it was the same, 2.0, respectively. The Bonferroni corrected post hoc test revealed the difference was significant between in-office and each of at-home whitening treatment groups ( $P=0.026$ and $P=0.03$, respectively), and no significant difference between two at-home whitening treatment groups $(\mathrm{P}>0.05)$ was found. neyjev test za post hoc korekciju i uzajamnu parnu usporedbu kategorija unutar različitih skupina izbjeljivanja.

Također je korišstena jednosmjerna ANOVA za ispitivanje razlika u srednjim vrijednostima $\Delta \mathrm{E}$ u trima različitim postupcima izbjeljivanja te Bonferronijev post hoc test ( $t$ test za parne uzorke) da bi se ispitale razlike unutar triju različitih postupaka izbjeljivanja. Razina značajnosti postavljena je na $0,05(5 \%)$.

\section{Rezultati}

Utvrđeno je da raspodjela procjene osjetljivosti zuba ispitanika prije izbjeljivanja i dan poslije dovršenih postupa$\mathrm{ka}, \mathrm{u}$ većini varijabli nije bila normalno distribuirana $(\mathrm{P}<$ $0,05)$ (slika 2., tablica 1.). Vrijednosti koeficijenta asimetrije i koeficijenta spljoštenosti kod dobivenih rezultata ispitanika upućuju na blagu asimetriju u odnosu prema krivulji zvona, $s$ blagim pomakom ulijevo (niže vrijednosti) i nižim razinama negoli u normalnoj raspodjeli (slika 2.). Jedina varijabla $s$ normalnom raspodjelom bila je procjena osjetljivosti zuba ispitanika jedan dan poslije tretmana izbjeljivanja 40-postotnim HP-om $(P>0,05)$ (slika 2., tablica 1.). Zato su u daljnjoj analizi provedena neparametrijska statistička ispitivanja.

Rezultati ispitivanja marginalne homogenosti dokazali su statistički značajnu razliku unutar procjena osjetljivosti zuba kod ispitanika prije i dan poslije tretmana izbjeljivanja 40-postotnim HP-om, te 16-postotnim i 10-postotnim CPom $(\mathrm{P}=0,000,0,000$ i 0,008$)$ (slika 3.). Rezultati ispitanika dan poslije svakog tretmana bili su znatno viši u usporedbi $s$ početnim rezultatima (slika 3$)(\mathrm{P}<0,05)$. Prosječne vrijednosti na početku i dan poslije tretmana izbjeljivanja 40-postotnim HPP-om bile su 1,4 i 6,2, poslije korištenja 16-postotnoga CP-a 1,9 i 3,0 te poslije upotrebe 10-postotnoga CP-a 1,7 i 2,2, respektivno (slika 3., tablica 2.) $(\mathrm{P}<0,05)$.

Istodobno se nisu razlikovali početni rezultati u svim trima različitim skupinama za izbjeljivanje, a Kruskal-Wallisov test otkrio je među njima samo male razlike u srednjim rankovima (tablica 3., P > 0,05). S druge strane, rezultati koji su procijenjeni dan nakon tretmana znatno su se razlikova$\mathrm{li}, \mathrm{s}$ najvišim prosječnim rankom za izbjeljivanje u ordinaciji 40-postotnim HP-om i najnižim srednjim rankom za izbjeljivanje kod kuće 10-postotnim CP-om (tablica 3., $\mathrm{P}<0,05$ ). Korištenjem Mann-Whitneyjeva testa za post hoc korekciju sa značajnošću postavljenom na $\mathrm{P}=0,016(\mathrm{P}=0,05 / \mathrm{broj}$ skupina) ta je razlika bila značajna samo između postupka izbjeljivanja 40-postotnim HP-om i 10-postotnim CP-om.

Distribucija srednjih vrijednosti $\Delta \mathrm{Eab}$ u trima različitim skupinama za izbjeljivanje bila je normalna (tablica 4.) $(\mathrm{P}>0,05)$. Jednosmjerna ANOVA potvrdila je statistički značajne razlike između srednjih vrijednosti $\triangle \mathrm{Eab}$. $\mathrm{U}$ postupku izbjeljivanja 40-postotnim HP-om u ordinaciji srednja promjena boje iznosila je 3,3, a pri uporabi 16-postotnoga i 10-postotnoga CP-a iznosila je 2,0. Bonferronijev post hoc test pokazao je da statistički značajna razliku u boji postoji između skupine kojoj su zubi izbjeljivani u ordinaciji i kod obiju skupina koje su postupak obavljale kod kuće $(P=0,026$; $\mathrm{P}=0,03)$. Iistodobno nije bilo statistički značajne razlike između dviju skupina koje su različitim postotcima $\mathrm{CP}-\mathrm{a}(\mathrm{P}>$ 0,05) izbjeljivale zube kod kuće. 

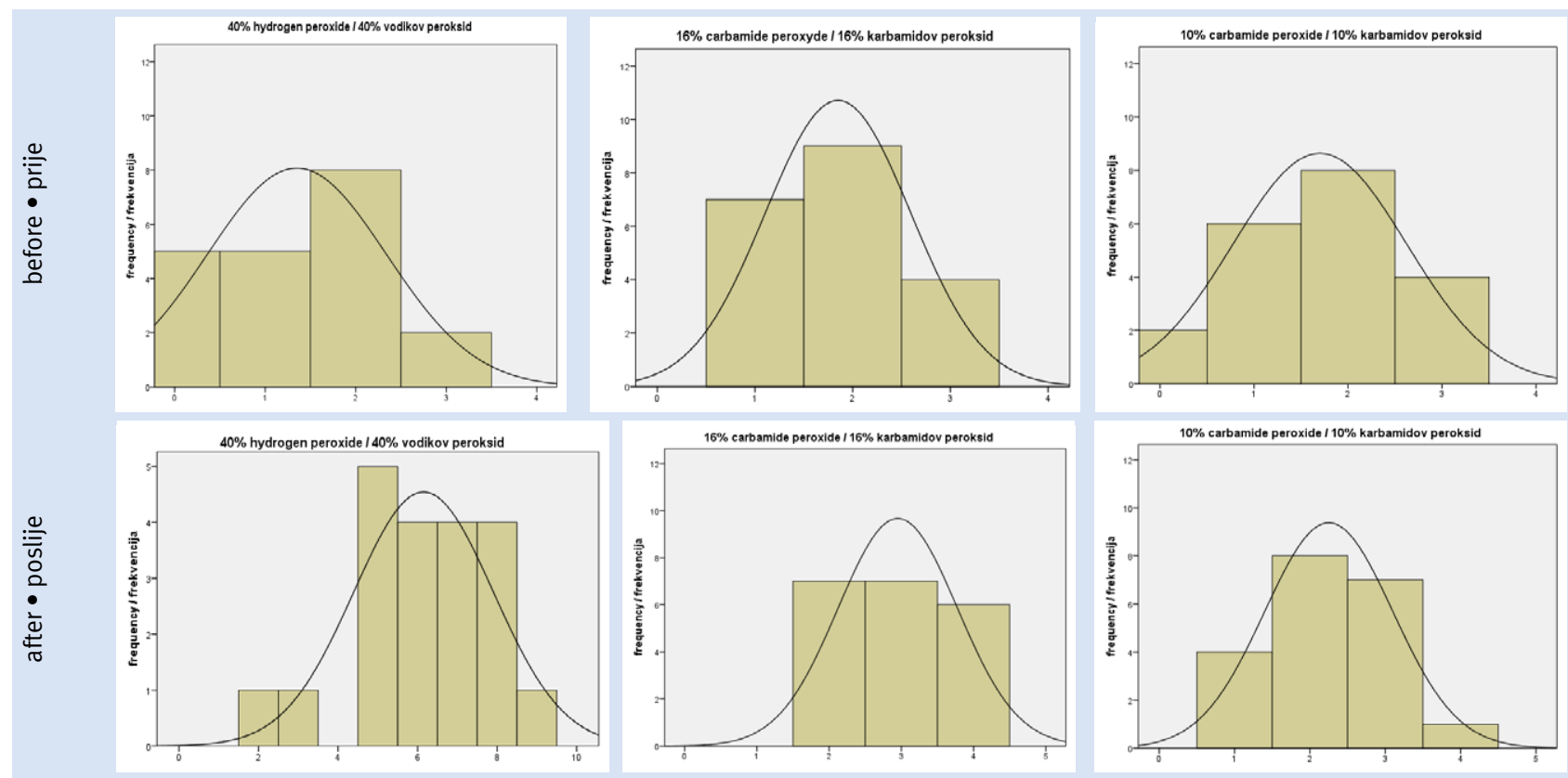

Figure 2 Histograms presenting deviation from normal distribution of data collected in this study.

Slika 2. Histogram odstupanja podataka prikupljenih u istraživanju od normalne distribucije

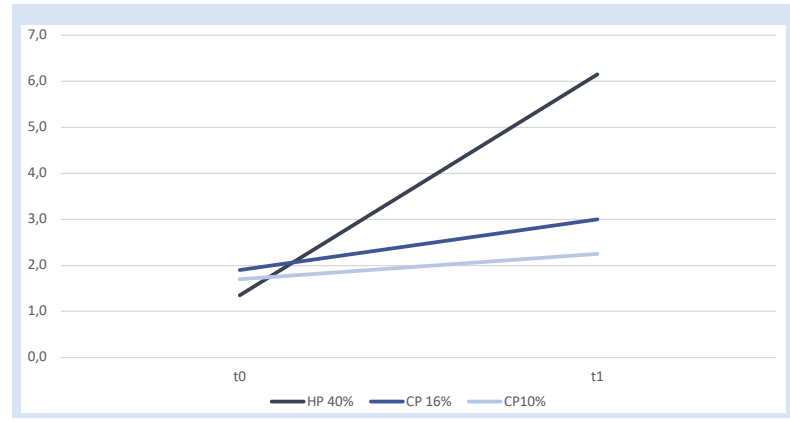

Figure 3 Mean values of the tooth sensitivity scores at the baseline and 1 day following whitening treatments using different concentration of HP and CP.

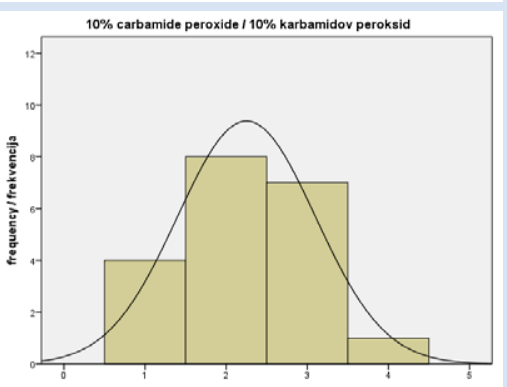

- ${ }^{\mathrm{HP}} 40 \%$ - $\mathrm{CP} 16 \%$ - ${ }^{\mathrm{CP} 10 \%}$

Slika 3. Srednje vrijednosti osjetlijivosti zuba prije dovršenih postupaka izbjeljivanja različitim koncentracijama HP-a i CP-a i dan poslije

Table 2 Patients' assessment of tooth sensitivity before and 1 day following three different whitening treatments and $P$ values ( $\mathrm{p}<0.05$ indicating not normal distribution)

Tablica 2. Pacijentova procjena osjetljivosti zuba prije i dan poslije korištenja triju različitih postupaka izbjeljivanja i P vrijednosti ( $p<0,05$ je normalna distribucija)

\begin{tabular}{|c|c|c|c|c|c|}
\hline & & $\begin{array}{l}\text { Median • } \\
\text { Medijan }\end{array}$ & $\begin{array}{l}\text { Skewness • } \\
\text { Iskrivljenost }\end{array}$ & Kurtosis & $P$ \\
\hline \multirow{2}{*}{$40 \% \mathrm{HP}$} & before $\cdot$ prije & 1.5 & -0.081 & -1.043 & 0.011 \\
\hline & 1 day following the treatment $\cdot 1$ dan nakon zahvata & 6.0 & -0.642 & 0.407 & $0.203 \mathrm{NS}$ \\
\hline \multirow{2}{*}{$16 \% \mathrm{CP}$} & before prije & 2.0 & 0.257 & -1.043 & 0.001 \\
\hline & 1 day following the treatment $\cdot 1$ dan nakon zahvata & 3.0 & 0.098 & -1.518 & 0.001 \\
\hline \multirow{2}{*}{$10 \% \mathrm{CP}$} & before $\cdot$ prije & 2.0 & -0.214 & -0.595 & 0.023 \\
\hline & 1 day following the treatment $\bullet 1$ dan nakon zahvata & 2.0 & 0.036 & -0.589 & 0.014 \\
\hline
\end{tabular}

Table 3 Significance of the differences in patients' assessment of tooth sensitivity using different concentrations of HP and CP before and 1 day following the treatment

Tablica 3. Značajnost razlika u pacijentovoj procjeni osjetljivosti zuba nakon upotrebe različitih koncentracija HP-a i CP-a prije i dan poslije postupka

\begin{tabular}{|c|c|c|c|c|c|}
\hline & & Rank $\bullet$ Rang & $\mathbf{X}^{2}$ & df $\bullet$ ss & $P$ \\
\hline \multirow{3}{*}{ before $\bullet$ prije } & $40 \% \mathrm{HP}$ & 25.88 & \multirow{3}{*}{2.550} & \multirow{3}{*}{2} & \multirow{3}{*}{0.259} \\
\hline & $16 \% \mathrm{CP}$ & 33.95 & & & \\
\hline & $10 \% \mathrm{CP}$ & 31.65 & & & \\
\hline \multirow{3}{*}{1 day following the treatment 1 dan nakon zahvata } & $40 \% \mathrm{HP}$ & 48.38 & \multirow{3}{*}{35.193} & \multirow{3}{*}{2} & \multirow{3}{*}{0.000} \\
\hline & $16 \% \mathrm{CP}$ & 25.88 & & & \\
\hline & $10 \% \mathrm{CP}$ & 17.25 & & & \\
\hline
\end{tabular}

$\mathrm{df} \bullet \mathrm{ss}$ - degree of freedom $\bullet$ stupnjevi slobode 
Table 4 Significance of the differences in tooth color changes $(\Delta E$ Eab) using different concentrations of HP and $C P$ Tablica 4. Značajnost razlike u promjeni boje zuba ( $\Delta$ Eab) pri primjeni različitih koncentracija HP-a i CP-a

\begin{tabular}{l|c|c|c|c|c|} 
& $\begin{array}{c}\text { Mean value } \\
\text { Srednja vrijednost }\end{array}$ & SD & F & df ss & P \\
\hline $40 \% \mathrm{HP}$ & 3.3 & 1.88 & & & \\
\hline $16 \% \mathrm{CP}$ & 2.0 & 1.46 & 4.853 & 2 & 0.011
\end{tabular}

$\mathrm{df} \bullet \mathrm{ss}$ - degree of freedom $\bullet$ stupnjevi slobode

\section{Discussion}

The null hypothesis was rejected as the application of different concentrations of HP and CPs using different techniques had significant effect on both tooth sensitivity increase and whitening results. The patients' scores of tooth sensitivity significantly increased following each of the treatments (Figures 2 and 3; Table 2$)(P<0.05)$. At the baseline, all of them reported a very low level of initial tooth sensitivity and there was no statistically significant difference between them (Table 3$)(p>0.05)$. The highest increase in tooth sensitivity following the whitening treatment was recorded in in-office procedure using the highest concentration of $\mathrm{HP}$ agent $(40 \%$ HP; Table 3$)(P<0.05)$. In this particular group, the participants reported their initial tooth sensitivity on NRC scale as slight pain (mean value was 1.4 ), but 1 day after the treatment it was moderate (mean value was 6.1). This was the only group whose final score shifted the threshold of mild sensitivity to moderate, which was expected since it had already been proven that higher concentrations of HP caused higher tooth sensitivity (25). In order to avoid the onset of severe pain and patients' suffering during the research, we have decided to assign to this group those participants who initially (at the baseline) reported the lowest level of the sensitivity (Figure 1). A significant increase in sensitivity in these two groups of at-home whitening treatments after the procedure was recorded too, but it was smaller and it remained within the range of (Figures 2 and 3$)(P<0.05)$. These results are in agreement with other studies confirming tooth sensitivity after et-home whitening to be mild $(15,16)$ and after in-office whitening to be moderate $(17,18$,) but in some cases even severe to that level that patients decided to abandon the procedure (19). Jorgensen et al. reported mild tooth sensitivity to be expected in about one-half of patients who undertake athome whitening treatment using $16 \% \mathrm{CP}, 10 \%$ of patients to experience moderate sensitivity, and $4 \%$ to experience severe sensitivity for one to two weeks (26). Kihn et al. reported no significant difference in sensitivity of the teeth in the 10\% CP and 15\% CP groups at the end of the study period and the same was confirmed in our study too (27).

Generally, when it comes to analyzing research in the field of dental whitening it is difficult to compare the results due to different concentrations of materials used, different protocols and techniques implemented and inconsistent monitoring periods in research. The same is true for our study. Usually, the researchers ask patients to assess tooth sensitivity following the whitening treatment considering it excluded upon exclusion criteria, but the authors of this study find it almost impossible for participants never to experience any

\section{Rasprava}

Nulta je hipoteza odbačena jer je primjena različitih koncentracija HP-a i CP-a s različitim tehnikama značajno utjecala na povećanje osjetljivosti zuba i na rezultate izbjeljivanja. Osjetljivost zuba pacijentima značajno se povećala nakon svakog postupka izbjeljivanja (slike 2. i 3., tablica 2.) $(\mathrm{P}<0,05)$. $\mathrm{Na}$ početku su svi prijavili vrlo nisku razinu početne osjetljivosti zuba i nije bilo statistički značajne razlike među njima (tablica 3.) ( $\mathrm{p}>0,05)$. Najveći porast osjetljivosti nakon postupka izbjeljivanja zabilježen je u ordinaciji poslije korištenja najveće koncentracije HP-a $(40 \%$, tablica 3.) $(\mathrm{P}<0,05)$. $\mathrm{U}$ toj su skupini sudionici prijavili početnu osjetljivost zuba na NRC ljestvici kao blagu bol (srednja vrijednost iznosila je 1,4 ), ali dan poslije postupka bila je umjerena (srednja vrijednost iznosila je 6,1). Radilo se o jednoj skupini čiji se prag blage osjetljivosti povisio u umjerenu, što je bilo i očekivano jer je već dokazano da veće koncentracije HP-a uzrokuju veću osjetljivost zuba (25). Kako bismo izbjegli pojavu jake boli i patnje ispitanika tijekom istraživanja, odlučili smo u tu skupinu uvrstiti one ispitanike koji su na početku prijavili najnižu razinu osjetljivosti (slika 1.). Početna razina osjetljivosti zuba koju su prijavili ispitanici u drugim dvjema skupinama na početnoj se razini također nije značajno razlikovala, ali je bila nešto viša, no na NRC ljestvici ta se osjetljivost ipak smatra blagom (slika 3.) $(\mathrm{P}<0,05)$. Također je zabilježen znatan porast osjetljivosti u tim dvjema navedenim skupinama, ali bio je manji i ostao je u rasponu blage boli (slike 2. i 3.) $(\mathrm{P}<$ 0,05). Ti su rezultati u skladu s drugim studijama u kojima je potvrđeno da je osjetljivost zuba nakon izbjeljivanja kod kuće blaga $(15,16)$, a nakon postupka u ordinaciji umjerena (17, 18), no u nekim slučajevima čak i do te razine da su ispitanici odlučili odustati od daljnjeg sudjelovanja (19). Jorgensen i suradnici dokazali su da se očekuje blaga osjetljivost zuba kod otprilike polovine pacijenata koji se podvrgavaju izbjeljivanju kod kuće s pomoću 16-postotnoga CP-a, $10 \%$ pacijenata ima umjerenu osjetljivost, a $4 \%$ jaku osjetljivost tijekom jednoga do dva tjedna (26). Kihn i suradnici dokazali su da nema značajne razlike u osjetljivosti zuba u skupinama koje su se koristile 10-postotnim i 15-postotnim CP-om, što je također potvrđeno u našem istraživanju (27).

Općenito, kada je u pitanju usporedba istraživanja u području izbjeljivanja zuba, teško je usporediti rezultate $s$ drugima zbog različitih koncentracija korištenih materijala, različitih protokola i tehnika te nedosljednih razdoblja praćenja. Tako je is našim istraživanjem. Obično istraživači traže od ispitanika da procijene osjetljivost zuba samo poslije tretmana za izbjeljivanje jer smatraju pojavu boli kriterijem za isključivanje, ali autori ovog istraživanja ističu da je gotovo nemo- 
type of clinically relatively irrelevant tooth sensitivity, even in those cases where participants have completely intact and healthy teeth and gums. In our exclusion/inclusion criteria (Table 1) we have eliminated those to whom a particular condition in the mouth can clinically cause any type of tooth sensitivity. Nonetheless, when asked, the participants at the baseline self-reported a very low but existing level of sensitivity (Figures 1 and 2). We believe our results can contribute to clinical work upon making decisions about material and techniques to be used in cases where patients self-report certain level of sensitivity despite the lack of clinical signs of sensitivity.

The results of our study confirmed a significant color change after $40 \% \mathrm{HP}, 16 \% \mathrm{CP}$ and $10 \% \mathrm{CP}$ whitening treatments. The color change for in-office treatment significantly differed from both at-home treatments as it was expected and already confirmed in other studies $(P<0.05)$. Again, it is difficult to compare the results due to differences in the assessment conducted immediately, one or two days, week or two following the treatment. Compared with the results of $\mathrm{Ma}$ tis et al. study, which compared several different whitening studies, the $\Delta \mathrm{E}_{\mathrm{ab}}$ for in-office treatment in our study matches theirs regarding a week after the procedure (28). However, our at-home whitening $\Delta \mathrm{E}_{\mathrm{ab}}$ for both $\mathrm{CP}$ concentrations was significantly lower than their $\Delta \mathrm{E}_{\mathrm{ab}}$ (28). One of the reasons probably lies in the fact that they evaluated 25 different whitening products in total, and we included in our research relatively younger participants with relatively lighter teeth at the baseline. Although somewhat lower, $\Delta \mathrm{E}_{\mathrm{ab}}$ values for inoffice whitening treatment in our study were above both the 50:50\% perceptibility threshold (PT) and 50:50\% acceptability threshold (AT) $(\mathrm{AT}=2.7, \mathrm{PT}=1.2)$, and $\Delta \mathrm{E}_{\mathrm{ab}}$ values for two different at-home whitening treatments were above the 50:50\% perceptibility threshold (PT) in dentistry proving that the procedures were successful (29).

As already mentioned, higher concentrations of HP and $\mathrm{CP}$ have been strongly related to higher incidence of post treatment (28). Therefore, to get faster results with less tooth sensitivity, some authors proposed the combined whitening technique consisting of a single in-office whitening session using lower concentrations of HP, followed by at-home whitening. Some studies reported that a combination of techniques has reduced the risk of tooth sensitivity and gum irritation, thus achieving good results in tooth whitening (30-34). This technique is specially recommended within the EU countries because of the special EU Directive recommending the usage of lower concentrations of HP for in-office whitening treatments (35). It has to be mentioned that this study was conducted out of EU and it is not under their jurisdiction; therefore we were allowed to use high concentrations of HP to prove that such a concentration particularly causes the highest level of tooth sensitivity, is therefore not recommended for the patients reporting low level of tooth sensitivity before the treatment.

The limitation of this study is a relatively young sample with participants having lighter teeth. Our further study will expand the sample size and include those with darker teeth. guće da ispitanici uopće ne dožive bilo koju vrstu klinički razmjerno nevažne osjetljivosti zuba, čak ako imaju potpuno intaktne i zdrave zube i desni. U našim kriterijima za isključenje/uključenje (tablica 1.) eliminirali smo one kojima određeno stanje u ustima može klinički prouzročiti bilo koju vrstu osjetljivosti zuba, no unatoč tomu ispitanici su sami izvijestili o vrlo niskoj početnoj razini osjetljivosti (slike 1. i 2.). Pretpostavljamo da naši rezultati mogu u kliničkome radu pomoći pri donošenju odluka o materijalu i tehnikama koje će se koristiti u slučaju kada pacijenti sami prijave određenu razinu osjetljivosti, unatoč nedostatku njezinih kliničkih znakova.

Rezultati našeg istraživanja potvrdili su značajnu promjenu boje nakon tretmana izbjeljivanja 40-postotnim HP-om te 16-postotnim i 10-postotnim CP-om. Promjena boje u procesu izbjeljivanja u ordinaciji značajno se razlikovala od oba tretmana kod kuće - to se i očekivalo i već potvrdilo u drugim istraživanjima $(\mathrm{P}<0,05)$. Ponovno je teško usporediti rezultate zbog razlika u procjeni provedenoj odmah, zatim jedan ili dva dana, te tjedan ili dva poslije postupka izbjeljivanja. Usporedba rezultata u istraživanju Matisa i suradnika koji su uspoređivali različita istraživanja o promjeni boje $\Delta \mathrm{Eab}$ poslije intenzivnog izbjeljivanja, pokazala je da se naši rezultati podudaraju $s$ njihovima izmjerenima tjedan dana poslije postupka (28). No, u našem istraživanju izbjeljivanja kod kuće i $\Delta$ Eab za obje koncentracije CP-a bio je značajno niži od njihova $\Delta \mathrm{Eab}$ (28). Jedan od razloga jest u činjenici da su se oni koristili s ukupno 25 različitih proizvoda za izbjeljivanje i zato što smo naše istraživanje proveli na razmjerno mlađim sudionicima s relativno svjetlijim zubima na početku. Iako su bile nešto niže, vrijednosti $\Delta$ Eab za izbjeljivanje u ordinaciji u našoj studiji bile su i iznad $50: 50 \%$ praga osjetljivosti (PT) i $50: 50 \%$ praga prihvatljivosti (AT) $(\mathrm{AT}=2,7, \mathrm{PT}=$ $1,2)$ i $\Delta$ Eab vrijednosti za dva različita postupka izbjeljivanja kod kuće bile su iznad $50: 50 \%$ praga osjetljivosti (PT) u stomatologiji, što je pokazalo da su zahvati bili uspješni (29).

Kao što je već istaknuto, veće koncentracije HP-a i CPa usko su povezane s većom učestalošću nakon zahvata (28). Zato su neki autori, kako bi se brže dobili rezultati s manjom osjetljivošću zuba, predložili kombiniranu tehniku izbjeljivanja koja se sastoji od jedne sesije izbjeljivanja u ordinaciji primjenom niže koncentracije HP-a, nakon čega slijedi izbjeljivanje kod kuće. Istraživanja su pokazala da je kombinirana tehnika smanjila rizik od osjetljivosti zuba i iritacije desni te postigla dobre rezultate kad je riječ o izbjeljivanju (30 - 34). Ta se tehnika posebno preporučuje u zemljama EU-a zbog Direktive Unije u kojoj se preporučuju niže koncentracije HP-a za izbjeljivanje u ordinaciji (35). Mora se napomenuti da je ovo istraživanje provedeno izvan EU-a i nije u njegovoj nadležnosti pa nam je dopušteno koristiti se visokim koncentracijama HP -a kako bismo dokazali da ta koncentracija posebno uzrokuje najveću razinu osjetljivosti zuba i zato se ne preporučuje za pacijente koji su prijavili nisku razinu osjetljivosti zuba prije izbjeljivanja.

Ograničenje ovog istraživanja bio bi uzorak razmjerno mladih ispitanika sa svjetlijim zubima. $U$ budućem istraživanju povećat ćemo uzorak i uključiti ispitanike s tamnijom bojom zuba. 


\section{Conclusions}

There was a significant increase in the level of tooth sensitivity 1 day following all three whitening treatments. The highest tooth sensitivity occurred after $40 \% \mathrm{HP}$ whitening treatment, and lowest after $10 \% \mathrm{CP}$ whitening treatment. In the range of color change, the $10 \% \mathrm{CP}$ was as effective as $16 \%$ CP whitening treatment. Therefore, in case with slight tooth sensitivity reported at the baseline, the $10 \% \mathrm{CP}$ whitening treatment should be recommended.

\section{Conflict of interest}

\section{The Authors declare no conflict of interest.}

Author's contribution: A.P. - Procurement of materials, Investigation, writing and editing; M.S. - Methodology, writing and editing, interpretation of results. D.I. - Statistical data processing, interpretation of results; D.K.Z. - Data collection and statistical processing, writing and editing

\section{Zaključci}

Znatno povećanje razine osjetljivosti zuba dogodilo se dan poslije završetka svih triju tretmana izbjeljivanja. Najveća osjetljivost zabilježena je nakon izbjeljivanja 40-postotnim HP-om, a najniža nakon postupka 10-postotnim CPom; u rasponu promjene boje izbjeljivanje 10-postotnim CP-om bilo je jednako učinkovito kao izbjeljivanje 16-postotnim CP-om. Zato, u slučaju blage osjetljivosti zuba prijavljene na početku, bilo bi dobro obaviti izbjeljivanje 10-postotnim CP-om.

\section{Sukob interesa}

Autori nisu bili u sukobu interesa.

Doprinos autora: A. P. - osiguranje materijala, odabir ispitanika, provedba istraživanja i skupljanje podatake, pisanje teksta; M. S. - metodologija, pisanje i uređivanje, interpretacija rezultata; D. I. - statistička obrada podataka, interpretacija rezultata; D. K. Z. - prikupljanje i statistička obrada podataka, pisanje i uređivanje

\begin{abstract}
Sažetak
Cilj: Cilj ove kliničke studije bio je usporediti rezultate osjetljivosti zuba i vrijednosti promjene boje prije izbjeljivanja u ordinaciji i kod kuće različitim koncentracijama sredstava za izbjeljivanje i jedan dan poslije. Materijal i metode: $U$ istraživanje je bilo uključeno ukupno 60 sudionika podijeljenih u tri skupine. Postupak izbjeljivanja proveden je 40-postotnim vodikovim peroksidom (HP) za izbjeljivanje u ordinaciij, te 16-postotnim, odnosno 10-postotnim karbamidnim peroksidom (CP) za postupak kod kuće. Sudionici su ocijenili osjetljivost zuba na početku postupka izbjeljivanja i dan poslije završetka. Rezultati: Pri svakom postupku izbjeljivanja rezultati za osjetljivost zuba značajno su se povećali nakon zahvata $(p<0,05)$. Najveći porast zabilježen je za postupak u ordinaciji 40-postotnim HP-om, a najmanja osjetljivost zabilježena je za izbjeljivanje kod kuće 10-postotnim CP-om $(p<0,05)$. Najveća promjena boje nakon postupka izbjeljivanja uočena je u skupini za izbjeljivanje u ordinaciji (40-postotni HP) (3.3) i značajno se razlikovala od izbjeljivanja 16-postotnim i 10-postotnim CP-om kod kuće čija je razlika u boji bila 2,0 ( $\mathrm{p}<0,05)$. Zaključak: Nakon postupka izbjeljivanja najmanju osjetljivost zuba prouzročilo je sredstvo za izbjeljivanje kod kuće s niskom koncentracijom CP-a u usporedbi s višim koncentracijama CP-a za kućno izbjeljivanje i HP-a za izbjeljivanje u ordinaciji, $s$ istom učinkovitošću u promjeni boje kao i sredstvo s visokim koncentratom CP-a. U slučaju da je blaga osjetljivost zuba prijavljena prije početka postupka, bilo bi dobro obaviti izbjeljivanje 10-postotnim CP-om.
\end{abstract}

Zaprimljen: 14 . veljače 2021 . Prihvaćen: 25. kolovoza 2021.

Adresa za dopisivanje

Amar Piknjač

Privatna stomatološka ordinacija

Floss i Gloss

Maršala Tita 5

71000 Sarajevo

Bosna i Hercegovina

amar.piknjac@gmail.com

MeSH pojmovi: izbjeljivanje zubi; osjetljivost dentina; sredstva za izbjeljivanje zubi

Ključne riječi: osjetljivost zuba, izbjeljivanje $u$ ordinaciji, izbjeljivanje kod kuće

\section{References}

1. Joiner A, Luo W. Tooth colour and whiteness: A review. J Dent. 2017 Dec;67S:S3-S10.

2. Vaez SC, Correa ACC, Santana TR, Santana MLC, Peixoto AC, Leal PC, Faria-e-Silva AL. Is a Single Preliminary Session of In-office Bleaching Beneficial for the Effectiveness of At-home Tooth Bleaching? A Randomized Controlled Clinical Trial. Oper Dent. Jul/ Aug 2019;44(4):E180-E189.

3. Samorodnitzky-Naveh GR, Grossman Y, Bachner YG, Levin L. Patients self-perception of tooth shade in relation to professionally objective evaluation. Quintessence Int. 2010;138(6):805-8.

4. Basting RT, Amaral FLB, Franca FMG, Florio FM. Clinical comparative study of the effectiveness and tooth sensitivity to $10 \%$ and $20 \%$ carbamide peroxide home-use and 35\% and 38\% hydrogen peroxide in-office bleaching materials containing desensitizing agents. Oper Dent. Sep-Oct 2012;37(5):464-73.

5. Dahl JE, Pallesen U. Tooth bleaching-a critical review of the biological aspects. Crit Rev Oral Biol Med. 2003;14(4):292-304.

6. Matis BA, Mousa HN, Cochran MA, Eckert GJ. Clinical evaluation of bleaching agents of different concentrations. Quintessence Int. 2000;31(5):303-10.

7. Mokhlis GR, Matis BA, Cochran MA. A clinical evaluation of carbamide peroxide and hydrogen peroxide whitening agents during daytime use. J Am Dent Assoc. 2000 Sep; 131(9):1269-77.

8. Matis BA, Cochran MA, Eckert G, Carlson TJ. The efficacy and safety of a $10 \%$ carbamide peroxide bleaching gel. Quintessence Int. 1998;29(9):555-63.
9. Metz MJ, Cochran MA, Matis BA, Gonzalez C, Platt JA, Lund MR. Clinical evaluation of $15 \%$ carbamide peroxide on the surface microhardness and shear bond strength of human enamel. Oper Dent. Sep-Oct 2007;32(5):427-36.

10. Browning WD, Blalock JS, Frazier KB, Downey MC, Myers ML. Duration and timing of sensitivity related to bleaching. J Esthet Restor Dent. 2007;19(5):256-64; discussion 264.

11. Browning WD, Chan DC, Myers ML, Brackett WW, Brackett MG, Pashley DH. Comparison of traditional and low sensitivity whiteners. Oper Dent. 2008;33(4):379-85.

12. Matis BA, Cochran MA, Franco M, al Ammar W, Eckert GJ, Stropes $M$. Eight in-office tooth whitening systems evaluated in vivo: a pilot study. Oper Dent. Jul-Aug 2007;32(4):322-7.

13. Da Costa JB, McPharlin R, Paravina RD, Ferracane JL. Comparison of at-home and in-office tooth whitening using a novel shade guide. Oper Dent. Jul-Aug 2010;35(4):381-8.

14. Markowitz K. Pretty painful: Why does tooth bleaching hurt? Med Hypotheses. 2010 May;74(5):835-40.

15. Rezende M, Loguerico AD, Reis A, Kossatz S. Clinical effects of exposure to coffee during at-home vital bleaching. Oper Dent. NovDec 2013;38(6):E229-36.

16. de Geus JL, Bersezio, Urrutia J, Yamada T, Fernandez E, Loguercio AD, Reis A, Kossatzs S. Effectiveness of and a tooth sensitivity with at-home bleaching in smokers: A multicenter clinical trial. J Am Dent Assoc. 2015 Apr;146(4):233-40. 
17. Ozcan M, Abdin S, Sipahi C. Bleaching induced tooth sensitivity: Do the existing enamel craze lines increase sensitivity? A clinica study. Odontology. 2014 Jul;102(2):197-202.

18. Paula E, Kossatz S, Fernandes D, Loguerico A, Reis A. The effect of perioperative Ibuprofen use on tooth sensitivity caused by in-office bleaching. Oper Dent. Nov-Dec 2013;38(6):601-8.

19. do Amaral FL, Sasaki RT, da Silva TC, Franca FM, Florio FM, Basting RT. The effects of home-use and in-office bleaching treatments on calcium and phosphorus concentrations in tooth enamel: An in vivo study. J Am Dent Assoc. 2012 Jun;143(6):580-6.

20. Zekonis R, Matis BA, Cochran MA, Al Shetri SE, Eckert GJ, Carlson TJ. Clinical evaluation of in-office and at-home bleaching treatments. Oper Dent. Mar-Apr 2003;28(2):114-21.

21. Haefeli M, Elfering A. Pain assessment. Eur Spine J. 2006 Jan;15 Suppl 1(Suppl 1):S17-24.

22. Gómez-Polo C, Gómez-Polo M, Martínez Vázquez de Parga JA, Celemín-Viñuela A. Clinical Study of the 3D-Master Color System among the Spanish Population. J Prosthodont. 2018 Oct;27(8):708-715.

23. Knezović D, Zlatarić D, Illeš IŽ, Alajbeg $M$, Žagar. In Vivo Evaluations of Inter-Observer Reliability Using VITA Easyshade ${ }^{\circledR}$ Advance 4.0 Dental Shade-Matching Device. Acta Stomatol Croat. 2016 Mar;50(1):34-9.

24. Knezović D, Zlatarić D, Illeš IŽ, Alajbeg M, Žagar. In Vivo and in Vitro Evaluations of Repeatability and Accuracy of VITA Easyshade ${ }^{\circledR}$ Advance 4.0 Dental Shade-Matching Device. Acta Stomatol Croat. 2015 Jun;49(2):112-8.

25. Machado LS, Anchieta RB, dos Santos PH, Briso AL, Tovar N, Janal $M N$, et al. Clinical Comparison of At-Home and In-Office Dental Bleaching Procedures: A Randomized Trial of a Split-Mouth Design. Int J Periodontics Restorative Dent. Mar-Apr 2016;36(2):251-60.
26. Jorgensen MG, Carroll WB. Incidence of tooth sensitivity after home whitening treatment. J Am Dent Assoc. 2002 Aug;133(8):1076-82; quiz 1094-5.

27. Kihn PW, Barnes DM, Romberg E, Peterson K. A clinical evaluation of 10 percent vs. 15 percent carbamide peroxide tooth-whitening agents. J Am Dent Assoc. 2000 Oct;131(10):1478-84.

28. Matis BA, Cochran MA, Eckert $G$. Review of the effectiveness of various tooth whitening systems. Oper Dent. Mar-Apr 2009;34(2):230-5.

29. Paravina RD, Ghinea R, Herrera LJ, Bona AD, Igiel C, Linninger $\mathrm{M}$, et al. Color difference thresholds in dentistry. J Esthet Restor Dent. Mar-Apr 2015;27 Suppl 1:S1-9.

30. Kugle G, Perry RD, Hoang E, Scherer W. Effective tooth bleaching in 5 days: using a combined in-office and at-home bleaching system. Compend Contin Educ Dent. 1997 Apr;18(4):378, 380-3.

31. Matis Ba, Cochran MA, Wang G, Eckert G). A clinical evaluation of two in-office bleaching regimens with and without tray bleaching. Oper Dent. Mar-Apr 2009;34(2):142-9.

32. de Geus JL, Wambier LM, Kossatz S, Loguerico AD, Reis A. Athome vs in-office bleaching: A systematic review and meta-analysis. Oper Dent. Jul-Aug 2016;41(4):341-56.

33. Knezović Zlatarić D, Žagar M, Illeš D. A clinical study assessing the short-term efficacy of combined in-office/at-home whitening treatment. J Esthet Restor Dent. 2019 Mar;31(2):140-146.

34. MeSH Browser [database on the Internet]. Council Directive 2011/84/EU of 20 September 2011 amending Directive 76/768/ EEC, concerning cosmetic products, for the purpose of adapting Annex III thereto to technical progress Text with EEA relevance. Available from: http://data.europa.eu/eli/dir/2011/84/oj. 